\title{
The Relationships between Life Skills and Post- graduation Employment for Top College Student Wrestlers in Japan
}

\author{
Seshito Shimizu$^{1}$, Kohei Shimamoto ${ }^{2}$ and Hironobu Tsuchiya ${ }^{3}$ \\ ${ }^{1}$ Athlete Pathway Development Project Japan Wrestling Federation \\ 3-15-1 Nishigaoka,Kita-Ku Tokyo,115-0056 \\ seshito@gmail.com \\ ${ }^{2}$ Graduate School of Education Hyogo University of Teacher Education \\ 942-1 Shimokume Kato Hyogo 673-1494 \\ ${ }^{3}$ Osaka University of Health and Sport Sciences \\ 1-1 Asashirodai Kumatori Sennan Osaka 590-0496 \\ [Received July 31, 2014; Accepted February 12, 2015; Published online February 24, 2015]
}

\begin{abstract}
The purpose of this study was to investigate the relationships between life skills and post-graduation employment for top college student athletes. In March 2011, 24 Japanese top level male wrestlers (mean age $=\mathbf{2 2 . 0} \pm \mathbf{0 . 2}$ ) who had graduated from university in March 2011 answered to the Appraisal Scale of Required Life Skills for College Student Athletes (Shimamoto et al., 2013). This scale has following 10 subscales: stress management, setting goals, thinking carefully, appreciating others, communicating, maintaining etiquette and manners, always making one's best effort, taking responsibility for one's own behavior, being humble, and maintaining physical health and well-being. The relationships between life skills acquisition level assessed in March 2011 and employment situations (employed or unemployed) by March 2012 were examined with nine members who had not obtained employment by the time of graduation from university. The analysis results showed that the employment group $(n=4)$ who had acquired employment within one year of graduation indicated a higher acquisition level compared to the unemployed group $(n=5)$ with regard to setting goals $(p<.05)$. Therefore, it was suggested that there is the positive relationship between setting goals and post-graduation employment for top college student wrestlers.
\end{abstract}

Keywords: employment, athlete career, top college student athletes, life skills, wrestlers

\section{Introduction}

Japan is currently in a period of long-term economic stagnation, and the consequential decline in the overall employment rate of university graduates is an increasingly serious issue. Top college student athletes - those training for international competitions such as Olympic Games and those involved in sports at an extremely high level - have less time available for academic study and employment-seeking activities as a result of training and competitions; this can make it more difficult for student athletes to acquire employment without obstacle after graduation. Many athletes cannot even job hunt as they are frequently unavailable due to their daily training, camps, and overseas competitions. Shimizu et al. (2010), for example, have compared the employment rates of top level college student athletes (specifically, wrestlers) and of other students, and reported that the employment rate upon graduation is higher for the non-athlete group (wrestlers $57.0 \%$, non-athletes $65.5 \%$ ).

Section 3 of the Sport Basic Plan, formulated in March 2012, notes the need to "enlighten top athletes on "dual careers" and promote scholarships and other support for their career formation" (Ministry of Education, Culture, Sports, Science and Technology (MEXT), 2012); this is a clear reference to the importance of providing education and support for the career formation of top athletes. Despite such initiatives, only a few studies or surveys have being carried out until now on the career issues of top college student athletes in Japan. The issue of the athletes' future careers is also an issue pertaining 
to the athletes' life event (a significant event in a person's life time), therefore, in order to formulate how to support the careers of top athletes in universities, it is imperative to examine the life skills, which is defined by "life skills augment a person's ability to cope with future (life) events"' (Danish et al., 1995) and the skills that allow the person to handle life events effectively.

Life skills comprise diverse skills, including goal setting, communication, and stress management skills. They are learnable psycho-social abilities and have been defined by the WHO (1994) as "abilities for adaptive and positive behavior that enable individuals to deal effectively with the demands and challenges of everyday life"'.

In today's sports education, in order to prevent problematic behaviors such as violence and abuse by athletes and also to nurture the athletes as successful individuals in society, life skill programs are being developed mainly in foreign countries to support athletes in acquiring life skills (e.g., Danish et al., 1995; Petitpas et al., 2004). Similarly, in Japan, practical activities to support athletes in acquiring life skills are being carried out in the various sport setting including baseball, soccer, soft tennis, and handball (Shimamoto et al., 2013).

A look at the body of research in Japan and overseas on sports and life skills reveals that most such research focuses on the introduction and explanation of life skills programs and how they work in practice, and the verification of the effects of such programs (e.g., Brunelle et al., 2007; Danish, 2002; Danish et al., 2005; Goudas and Giannoudis, 2008; Papacharisis et al., 2005). However, there is limited examination on whether life skills acquisition actually has a positive correlation to effective coping of life events. Shimizu and Shimamoto (2011) are examining the relationship between life skills acquisition and the employment rate of top level, male, senior year university wrestlers, but there has been no significant finding on the relationship. Furthermore, the examination results were based on analysis of a cross-sectional survey, therefore it fails to establish a clear relationship between both variables. Therefore, as mentioned in the report by Shimizu et al. (2010), long term longitudinal surveys should be conducted among the university athletes who cannot acquire employment during their university career, which are above half of all university athletes, to establish a relationship between life skills acquisition and employment rate.

Based on the above, this study conducted a tracking survey on university graduates who had been top athletes while in school. The survey was conducted over a one year period, with questionnaires conducted at two discrete time points. The purpose of the survey was to investigate the relationship between life skills at the time of graduation and acquisition of employment after graduation by focusing on those athletes who had not been able to acquire employment by the point of graduation.

\section{Method}

\subsection{Survey Participants and Survey Timing}

As Shimizu and Shimamoto (2011), Shimizu et al. (2010) are examining wrestlers as the choice of athletes in the research of the career development of retired top level university athletes, this research has chosen wrestlers as the survey participants as well. 24 male wrestlers who graduated university in March 2011 with a successful competitive record were chosen as the survey participants. These participants were chosen not only for their successful wrestling career but also because they were competing at mid to high level and were extremely limited with time for job hunting due to participating in overseas events and high level competitions. The average age of participants at the time of the first questionnaire was $22.0 \pm 0.2$ years. In order to minimize differences related to (1) method of enrollment, (2) living environment, (3) training time, (4) competitive level of college of enrollment, participants who met the parameters for (1)-(4) above, as summarized in Table 1, were selected from among former top college student athletes who studied at private universi-

Table 1 Factors Common to All Survey Participants

\begin{tabular}{ll}
\hline $\begin{array}{l}\text { (1) Method of university en- } \\
\text { rollment }\end{array}$ & $\begin{array}{l}\text { Enrolled on a sports scholar- } \\
\text { ship after oustanding perfor- } \\
\text { mance in sports during high } \\
\text { school }\end{array}$ \\
Dormitory equipped by uni- \\
versity sports clubs \\
6 days a week, training for ap- \\
prox. 1 hour in the morning, \\
approx. 2 hours in the after- \\
noon
\end{tabular}


ties in Tokyo and the neighboring prefecture of Kanagawa (5 universities in total, 4-5 students from each university); these proximate locations were selected in order to minimize environmental differences over the four year undergraduate period.

The survey was conducted between the end of March 2011 and the beginning of March 2012, with initial and follow-up questionnaires given to all participants at those two points (hereinafter, initial questionnaire, follow-up questionnaire). Subsequent analysis was based on the 9 participants, of the total of 20 participants who completed both questionnaires (successive response rate, 83.3\%), who had not been successful in acquiring employment by the point of graduation. Of these 9 participants, 4 had acquired employment by the followup questionnaire (hereinafter referred to as the " $\mathrm{em}$ ployed group") and 5 had yet to acquire employment ("unemployed group").

\subsection{Procedure}

Before conducting the initial questionnaire, the managers and coaches of the wrestling teams of each target university were approached and given an outline of the survey purpose; the questionnaire was conducted at each target university after acquiring the permission of all participants. For the follow-up questionnaire, the researchers attempted to contact all survey participants (now graduates) by telephone, and where contact was made a questionnaire was posted to the relevant participant. The participant returned the questionnaire, immediately on completion, to the researchers. Participants were given a participation fee for each completed questionnaire. The terms of participation fee payment were explained to participants before the initial survey was conducted.

\subsection{Survey Content}

Appraisal Scale for Life Skills in College Student Athletes

This appraisal scale was developed by Shimamoto et al. (2013), based on the practical experiences of top level instructors at universities who have well accomplished credentials such as producing national champions; it formed the basis of the initial questionnaire. The appraisal scale comprises 10 psychosocial aspects used to evaluate life skills desirable in college student athletes, as follows:

- Stress management (e.g. trying to talk to someone when you are faced with a problem that you cannot resolve by yourself).

- Setting goals (e.g. drawing up specific plans to achieve a goal or objective).

- Thinking carefully (e.g. being able to analyze the reasons for success and failure).

- Appreciating others (e.g. always making your gratitude clear through verbal communication).

- Communicating (e.g. getting on with older and younger students and instructors, as well as your peers).

- Maintaining etiquette and manners (e.g. avoiding emotional and provocative behavior or verbal outbursts).

- Always making one's best efforts (e.g. able to approach even simple and repetitive tasks with diligence).

- Taking responsibility for one's own behavior (e.g. trying to avoid making the same mistake twice).

- Being humble (e.g. remaining aware that you are not always right).

- Maintaining physical health and well-being (e.g. getting enough sleep, making sure you are well rested each morning).

Participants respond by choosing from the four options the option that best describes their response, from 1: Strongly disagree to 4: Strongly agree; higher rating scores are interpreted as indicating high skill levels.

\subsection{Questions on Career Status}

Both the initial and follow-up questionnaires asked participants whether they had acquired employment at the time of each questionnaire, by requiring them to select between two options: "I have acquired employment" and "I have not yet acquired employment (including part-time employment)".

\subsection{Statistical Treatment}

In order to consider the impact of life skills on the acquisition of employment, this analysis focused on the employed and unemployed groups. The analysis compared the lowest scale scores from the life skills appraisal scale in the initial questionnaire using an unpaired t-test for both the employed and the unemployed. Statistical significance was set at $5 \%$. 


\section{Results}

Table 2 shows the basic statistical data and the results of the t-test for the lowest scoring aspects on the life skills appraisal scale obtained for the employed and unemployed groups in the initial survey.

Looking at the results of the t-test for "setting goals", in other words setting goals and drawing up a plan to achieve those goals, the mean value for the employed group was significantly higher than that of the unemployed group. There was no significant difference between the two groups for any of the other lowest scoring aspects.

In order to examine in detail the statistically sig- nificant difference seen in "setting goals", a further t-test was conducted on the four items comprising the lowest scoring skill aspects (See Table 3). The results indicated a statistically significant difference for two of those items: "I try to write down my goals and objectives rather than just thinking about them" and "I establish time-specific goals, for example weekly, monthly, or semiannually".

These results suggest the possibility that goal setting skills mentioned as core of life skills by Danish et al. (1993) would be positively related to acquisition of employment after college graduation for male wrestlers who were active in high-level competition and received the restriction of job hunting in university period.

Table 2 Basic Statics t-test Result for Life Skills in Survey Paticipants

\begin{tabular}{|c|c|c|c|c|c|c|c|c|c|}
\hline & \multicolumn{2}{|c|}{$\begin{array}{c}\text { Employed } \\
\text { group } \\
(n=4)\end{array}$} & \multicolumn{2}{|c|}{$\begin{array}{l}\text { Unemployed } \\
\text { group } \\
(n=5)\end{array}$} & \multirow{2}{*}{$\begin{array}{c}\mathrm{t} \\
\text { value }\end{array}$} & \multirow{2}{*}{$\begin{array}{c}\text { Mean } \\
\text { difference }\end{array}$} & \multicolumn{2}{|c|}{$\begin{array}{c}95 \% \\
\text { confidence }\end{array}$} & \multirow{2}{*}{$\begin{array}{c}\text { Cohen's } \\
\text { d }\end{array}$} \\
\hline & $\begin{array}{l}\text { Mean } \\
\text { value }\end{array}$ & SD & $\begin{array}{l}\text { Mean } \\
\text { value }\end{array}$ & SD & & & $\begin{array}{l}\text { Lower } \\
\text { bound }\end{array}$ & $\begin{array}{l}\text { Upper } \\
\text { bound }\end{array}$ & \\
\hline Stress management & 13.00 & 3.16 & 11.60 & 2.97 & .68 & 1.40 & -3.44 & 6.24 & .46 \\
\hline Setting goals & 12.75 & 2.50 & 8.40 & 1.82 & $3.04 *$ & 4.35 & .96 & 7.74 & 1.99 \\
\hline Thinking carefully & 14.25 & 1.71 & 11.20 & 2.17 & $2.29^{\dagger}$ & 3.05 & -.10 & 6.20 & 1.56 \\
\hline Appreciating others & 15.25 & 1.50 & 13.80 & 1.79 & 1.29 & 1.45 & -1.20 & 4.10 & .88 \\
\hline Communicating & 14.50 & 1.92 & 11.60 & 2.70 & 1.80 & 2.90 & -.90 & 6.70 & 1.24 \\
\hline Maintaining etiquette and manners & 12.25 & 2.22 & 12.80 & 3.11 & .30 & -.55 & -4.94 & 3.84 & -.21 \\
\hline Always making one's best efforts & 14.25 & 2.87 & 11.00 & 1.41 & $2.24^{\dagger}$ & 3.25 & -.18 & 6.68 & 1.44 \\
\hline Taking responsibility for one's own behavior & 14.25 & 1.71 & 13.20 & .84 & 1.22 & 1.05 & -.99 & 3.09 & .71 \\
\hline Being humble & 13.25 & 2.22 & 13.00 & 1.73 & .19 & .25 & -2.85 & 3.35 & .13 \\
\hline Maintaining physical health and well-being & 12.25 & 2.87 & 9.80 & 2.17 & 1.46 & 2.45 & -1.51 & 6.41 & .96 \\
\hline
\end{tabular}

Note 1) degree of freedom is 7 for all $t$ values

Note 2) ${ }^{\dagger} \mathrm{p}<.10 * \mathrm{p}<.05$

Table 3 t-test Results for Item Measured Settig Goals in Survey Participants

\begin{tabular}{|c|c|c|c|c|c|c|c|c|c|}
\hline & \multicolumn{2}{|c|}{$\begin{array}{l}\text { Employed } \\
\text { group } \\
(n=4)\end{array}$} & \multicolumn{2}{|c|}{$\begin{array}{l}\text { Unemployed } \\
\text { group } \\
(n=5)\end{array}$} & \multirow{2}{*}{$\begin{array}{c}\mathrm{t} \\
\text { value }\end{array}$} & \multirow{2}{*}{$\begin{array}{c}\text { Mean } \\
\text { difference }\end{array}$} & \multicolumn{2}{|c|}{$\begin{array}{l}95 \% \\
\text { confidence }\end{array}$} & \multirow{2}{*}{$\begin{array}{c}\text { Cohen's } \\
\text { d }\end{array}$} \\
\hline & $\begin{array}{l}\text { Mean } \\
\text { value }\end{array}$ & SD & $\begin{array}{l}\text { Mean } \\
\text { value }\end{array}$ & SD & & & $\begin{array}{l}\text { Lower } \\
\text { bound }\end{array}$ & $\begin{array}{l}\text { Upper } \\
\text { bound }\end{array}$ & \\
\hline $\begin{array}{l}\text { I write them down in my notebook/diary, in order } \\
\text { to maintain a strong sense of awareness of my goals }\end{array}$ & 3.25 & .50 & 2.00 & 1.00 & 2.26 & 1.25 & -.06 & 2.56 & 1.58 \\
\hline $\begin{array}{l}\text { I try to write down my goals and objectives rather } \\
\text { than just thinking about them }\end{array}$ & 3.25 & .96 & 1.80 & .84 & $2.43^{*}$ & 1.45 & .04 & 2.86 & 1.61 \\
\hline $\begin{array}{l}\text { I establish time-specific goals, for example weekly, } \\
\text { monthly, or six monthly }\end{array}$ & 3.00 & .82 & 1.80 & .45 & $2.83^{*}$ & 1.20 & .20 & 2.20 & 1.81 \\
\hline $\begin{array}{l}\text { I draw up specific action plans in order to achieve } \\
\text { goals }\end{array}$ & 3.25 & .96 & 2.80 & .84 & .75 & .45 & -.96 & 1.86 & .50 \\
\hline
\end{tabular}

Note 1) degree of freedom is 7 for all $t$ values

Note 2) $* \mathrm{p}<.05$ 


\section{Discussion}

It may be assumed that, for both the employed and unemployed groups, each member had acquired to have high motivation to patiently continue with job seeking by oneself. As the statements "an individual without goals is like a computer without programmes" (Mash et al., 1992) and "[goals] are the energy source that motivates individuals to action" (Danish et al., 1993), "setting goals" has close relationship with enhancement of motivation. Therefore, the analysis result which shows that setting goals positively related to acquisition of employment is valid. The difference in the time it took to acquire employment with the employed group and the unemployed group can be attributed to the difference in the quality of the goal setting which has a direct impact on motivation. The analysis results (Table 3) of the categories of setting goals supports the differences in the quality of the goal setting.

Looking first at the setting of incremental objectives, it has already been argued that "short-term goals can facilitate the achievement of long-term goals" (Locke and Latham, 1985); the setting of short- and medium-term goals may therefore have contributed to the motivation to achieve the longterm goal being maintained. However, it is likely the case that the longer it takes to achieve the (end) goal, the greater the decline in motivation. By establishing an action plan designed to facilitate attainment of the end goal, through the setting of short- and medium-term goals to be achieved by a certain date, it may be possible to sustain at a higher level the motivation to take action geared toward (end) goal attainment.

This study looked only at the example of male graduates who were leading wrestlers as college students; there is a clear need to conduct similar surveys on graduates who competed in different sports, in order to build up a larger body of work on those life skills closely related to the acquisition of employment after graduation. For "goal setting", the only life skill to demonstrate a statistically significant difference in this study, multiple programs focused on the acquirement of this life skill have already been developed both in Japan and internationally, including the Service Program focused on Goal Setting (SPG), comprising five lectures and practical training sessions (Ueno, 2006), and the Going for the Goal (GOAL) program (Danish, 1996), comprising ten workshops. Furthermore, the GOAL program represents a foundation for many of those programs, aimed at the acquisition of life skills through sport, being conducted in Japan and internationally (Sugiyama et al., 2008). Going forward, such programs, combined with the results of this study, are deserving of consideration if top level student athletes are to be provided with the support they need to acquire the goal-setting skills necessary to both enhance their careers as sports competitors, and to assist in the smooth transition to a non-competitive career. Moreover, the findings of this survey should be fed back to top level student athletes and instructors as widely as possible, in order to impact the motivation of athletes to participate in life skill acquisition programs. It is vital that athletes are made aware of the importance of acquiring life skills as part of the day-to-day process of competitive sports training, in addition to the prerequisite competitive skills.

\section{Conclusions}

This study aimed to verify the relationship between life skills at the time of graduation and acquisition of employment after college graduation, by conducting a tracking survey on former top college student athletes who were active in high-level male wrestling before graduation and had been unable to acquire employment by the time of graduation. As a result, it was shown that there is a positive relationship between setting goals and acquisition of employment. The result of this study suggested that supporting athletes in acquiring setting goals skills would be one of the directions of career development support for top level student athletes in the future.

\section{Acknowledgments}

The research was supported by the Sasakawa Sports Research Grant from Sasakawa Sports Foundation.

\section{References}

Brunelle, J., Danish, S. J., Forneris, T. (2007). The impact of a sport-based life skill program on adolescent prosocial values. Applied Developmental Science, 11: 43-55.

Danish, S. J. (1996). Interventions for enhancing adolescents' life skills. The Humanistic Psychologist, 24: 365-381.

Danish, S. J. (2002). Teaching life skills through sport. In: Gatz, M., Messner, M. A., and Ball-Rokeach, S. J. (Eds.) Paradoxes of youth and sport. (pp.49-60). Albany, NY: State 
University of NewYork Press.

Danish, S. J., Forneris, T., and Wallace, I. (2005). Sport-based life skills Programming in the schools. Journal of Applied School Psychology, 21: 41-62.

Danish, S. J., Petitpas, A. J., and Hale, B. D. (1993). Life development intervention for athletes: Life skills through sports. The Counseling Psychologist, 21: 352-385.

Danish, S. J., Petitpas, A. J., and Hale, B.D. (1995). Psychological interventions: A life development model. In: Murphy, S. M. (Ed.) Sport psychology interventions. (pp.19-38). Champaign, IL: Human Kinetics.

Goudas, M. and Giannoudis, G. (2008). A team-sports-based life skills program in a physical education context. Learning and Instruction, 18: 528-536.

Locke, E. A. and Latham, G. P. (1985). The application of goal setting to sports. J. Sport Exerc. Psychol., 7: 205-222.

Mash, J. M., Danish, S. J., and Farrell, A. D. (1992). How the future shapes the present: A study of low income urban youth. Unpublished manuscript

Ministry of Education, Culture, Sports, Science, and Technology (MEXT) Japan (2012). http://www.mext.go.jp/ component/a_menu/sports/detail/_icsFiles/afieldfile/2012/ 04/02/1319359_3_1.pdf (accessed 2013-5-10)

Papacharisis, V., Goudas, M., Danish, S. J., and Theodorakis, Y. (2005). The effectiveness of teaching a life skills program in a sport context. Journal of Applied Sport Psychology, 17: 247-254.

Petitpas, A. J., Van Raalte, J. L., Cornelius, A. E., and Presbrey, J. (2004). A life skills development program for high school student-athletes. Journal of Primary Prevention, 24: 325-334.

Shimamoto, K., Tokairin, Y., Murakami, K., and Ishii, M. (2013). Appraisal of required life skills for athletes: A scale development on college student athletes. Japanese Journal of Sport Psychology, 40: 13-30 (in Japanese with English abstract)

Shimizu, S. and Shimamoto, K. (2011). The relationship between career development and life skills acquisition in top student athletes.Bulletin of Nippon Sport Science University, 41: 111-116 (in Japanese)

Shimizu, S., Takahashi, Y., and Kono, I. (2010). A Comparison of Employment Situation of University Athletic Clubs Based on Differences in Instruction and Management: A Case of Wrestlers. Journal of Japan Society of Sports Industry, 20: 119-129 (in Japanese with English abstract)

Sugiyama, Y., Shibukura, T., Nishida, T., Ito, T., Sasaki, B., and Isogai, H. (2008). Current status and prospect of life skills education through physical education in schools. Jour- nal of health science, 30: 1-9 (in Japanese with English abstract)

Ueno, K. (2006). Relationship between acquisition of goal-setting skill and time perspective through participation in athletic clubs. Japan J. Phys. Educ. Hlth. Sport Sci, 51: 49-60 (in Japanese with English abstract)

World Health Organization. (1994). Life skills education in schools. Geneva, Switzerland: WHO.

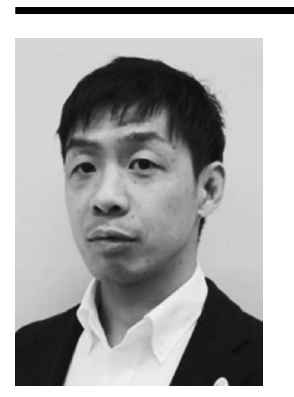

Name:

Seshito Shimizu

Affiliation:

Athlete Pathway Development Project Japan Wrestling Federation

Address:

3-15-1 Nishigaoka,Kita-Ku Tokyo,115-0056

Brief Biographical History:

2007-2009 Master's Program in Sports and Health Promotion Graduate School of University of Tsukuba

2010-2013 Assistant professor at Nippon Sports Science University

2013-current Project Manager of Athlete Pathway Development Project Japan Wrestling Federation

2014-current Doctoral Program in Graduate School of Osaka University of Health and Sport Sciences

\section{Main Works:}

-Shimizu, S. and Shimamoto, K. (2011). The relationship between career development and life skills acquisition in top student athletes. Bulletin of Nippon Sport Science University, 41(1): 111-116 (in Japanese)

-Shimizu, S., Takahashi, Y., and Kono, I. (2010). A Comparison of Employment Situation of University Athletic Clubs Based on Differences in Instruction and Management: A Case of Wrestlers. Journal of Japan Society of Sports Industry, 20(1): 119-129 (in Japanese with English abstract)

Membership in Learned Societies:

- Japanese Society of Sport Psychology

- Japan Society of Sports Industry

- Japan Society of Coaching Studies

- Japan Society of Physical Education, Health and Sport Sciences 